\title{
Replacement of 8-MOP/UV-A treatment by UV-C irradiation for further development of Extracorporeal Photopheresis
}

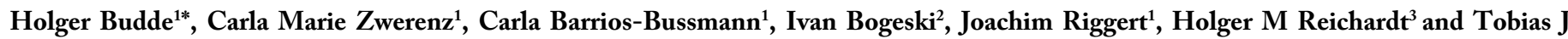 \\ Legler ${ }^{1}$ \\ ${ }^{1}$ Department of Transfusion Medicine, University Medical Center Göttingen, Göttingen, Germany \\ ${ }^{2}$ Molecular Physiology, Institute of Cardiovascular Physiology, University Medical Center, Germany \\ ${ }^{3}$ Institute for Cellular and Molecular Immunology, University Medical Center Göttingen, Göttingen, Germany
}

\begin{abstract}
Extracorporeal photopheresis (ECP) has been used for more than 30 years to treat inflammatory disorders such as graft-versus-host disease (GvHD). The central step is the ex vivo treatment of the patient's leukocytes with 8-Methoxypsoralen (8-MOP) and UV-A irradiation, resulting in cellular apoptosis. However, the injection of 8-MOP into the irradiation bag poses a risk of contamination. UV-C radiation is more energetic than UV-A radiation and is able to induce apoptosis without photosensitizers such as 8-MOP. Hence, we compared the effects of both treatments on leukocytes in vitro and in vivo. We analyzed the cell-specific pattern of apoptosis in human mononuclear cells treated with 8-MOP/UV-A and UV-C in cell culture for 72 hours. In addition, we investigated the therapeutic potential of UV-C irradiated leukocytes in a mouse model of acute GvHD. In vitro we observed equal or only slightly decreased levels of apoptosis in cells treated with UV-C compared to 8-MOP/UV-A. Both, the kinetic and final level of apoptosis after $72 \mathrm{~h}$ were similar in T cells, monocytes, B cells, regulatory T cells and NK(T) cells. The therapeutic in vivo analysis in a murine GvHD model revealed no clear benefit of the UV-C treatment compared to the non-therapeutic control group, but also no adverse survival or clinical GVHD score compared to the 8-MOP/UV-A group. Our in vitro and in vivo data support the notion that 8-MOP/UV-A could be replaced by UV-C treatment in ECP and thus contribute to a safer GvHD therapy. The investigation of the therapeutic in vivo potential should be continued in further studies.
\end{abstract}

\section{Introduction}

The impact of electromagnetic frequencies on life is tremendous. Frequencies in the range of the visible light are central for the homeostasis of the circadian rhythms of the nervous system and metabolism of the whole body [1,2]. On the other side unnatural microwave frequencies of modern wireless technologies (smartphones, cell towers and WiFi/WLAN) have devastating biological effects which are clearly proven by hundreds of scientific publications worldwide [310]. However, we can use frequencies of the ultraviolet (UV) spectrum for therapeutic purposes. UV therapy has actually a long history. Today the Extracorporeal Photopheresis (ECP), using 8-Methoxypsoralen (8-MOP) and UV-A light, is a widespread therapy for severe diseases linked to excessive immune reactions. A common indication for ECP therapy is Graft-versus-Host Disease (GvHD). GvHD is a major complication after allogeneic Hematopoietic Stem Cell Transplantation and responsible for the high morbidity and mortality in these patients [11]. ECP therapy is suitable for the treatment of both acute and chronic GvHD, especially because ECP is rather modulating the overwhelming immune response than suppressing the immune system in an unspecific way [12]. Many, but certainly not all, cellular mechanisms of ECP therapy have been identified [13]. The initial immunological mechanism is probably the induction of apoptosis by extra-corporal treatment of the patient's cells with 8-MOP and UV-A irradiation [14-19]. The lymphocytes are reinfused into the patient, undergo delayed apoptosis within 24-72 hours after treatment, and are subsequently phagocytized $[14,20,21]$. Apoptotic clearance is an elementary and well-known mechanism of immune homeostasis $[22,23]$. Apoptotic cells are removed by immature dendritic cells, which thereby become tolerogeneic dendritic cells [24]. Another theory postulates the induction of dendritic cells through the ex vivo interaction with platelets in the apheresis device itself [25].

From a more technical point of view, recent ECP research has focused on the replacement of 8-MOP by other photosensitizers such as 5-Aminolevulinic acid [26]. However, all these procedures require that 8-MOP or other photosensitizers which increase the patient's photosensitivity have to be added to the lymphocytes [27]. The injection of 8-MOP into the apheresis bag is a step that is prone to potential bacterial contamination. Although clinical experience shows that this risk is not very high, it could become a regulatory aspect in the technical ECP process. Another and clinically well-known side-effect is that 8-MOP can induce photoallergy in the patient [28]. To circumvent these issues, treatment of the cells by 8 -MOP and UV-A could possibly be replaced by using UV-C irradiation without adding 8-MOP. In the conventional ECP setup, apoptosis is induced by activating the

*Correspondence to: Holger Budde, Department of Transfusion Medicine, University Medical Center Göttingen, Robert-Koch-Str. 40, 37075 Göttingen, Germany, E-mail: holger.budde@med.uni-goettingen.de

Key words: photopheresis, ECP, UVC, apoptosis

Received: January 08, 2021; Accepted: January 18, 2020; Published: January 21 , 2020 
photosensitizer 8-MOP by UV-A light. UV-C frequencies have a higher energy level compared to UV-A. It was shown that UV-C light alone is sufficient to induce delayed apoptosis similar to 8-MOP/ UV-A treatment [29]. In addition, UVC was successfully tested for leukocyte inactivation in human platelet products [30]. Our hypothesis is therefore that UV-C treatment can replace 8-MOP/UV-A in ECP protocols. To address this issue, we investigated the apoptosis kinetics of several human leukocyte subpopulations treated with UV-C in vitro, in comparison to the standard protocol with 8-MOP/UVA. In addition, we used a mouse model of acute GvHD to explore safety and efficacy of UV-C treated leukocytes in vivo.

\section{Materials and methods}

\section{Blood samples}

Blood was drawn from healthy donors routinely visiting the blood donation service of the University Medical Center Göttingen. Female and male individuals aged 18-65 years were included. For every experimental condition 9-12 blood samples were used. Every donor gave written consent that part of their donated blood could be used for scientific purposes. The study was performed according to the Declaration of Helsinki and approved by the ethics committee of the University Medical Center Göttingen (approval no. 26/9/17).

Preparation of mononuclear cells was performed with the help of Ficoll-Paque Plus (GE Healthcare Biosciences AB, Uppsala, Sweden). Sodium-citrate was used as anticoagulant. Cellular separation was performed following a centrifugation protocol with $600 \mathrm{~g}$ for $20 \mathrm{~min}$ and two platelet depletion steps with $100 \mathrm{~g}$ for $10 \mathrm{~min}$.

\section{8-MOP/UVA and UVC treatment}

8-MOP was produced by the pharmacy of the University Medical Center Göttingen. Mononuclear cells were resuspended in $5 \mathrm{ml}$ PBS (Gibco, Life Technologies, Carlsbad, USA) in 25 ml flasks. For UV-A irradiation $\left(2 \mathrm{~J} / \mathrm{cm}^{2}\right)$, cells were incubated with $0.2 \mu \mathrm{g} / \mathrm{ml} 8$-MOP. UV-C irradiation was performed without 8 -MOP at 2 and $6 \mathrm{~J} / \mathrm{cm}^{2}$, respectively. After irradiation, 8-MOP was removed by centrifugation at $350 \mathrm{~g}$ for $10 \mathrm{~min}$.

For the in vitro apoptosis analysis, cells were cultured after treatment in RPMI-1640 medium (Gibco, Thermo Fischer, Waltham, USA) supplemented with $10 \%$ fetal bovine serum (Gibco) and $1 \%$ penicillin/streptomycin (Gibco) at $37^{\circ} \mathrm{C}$ and $5 \% \mathrm{CO}_{2}$ for up to $72 \mathrm{~h}$.

\section{GvHD mouse model}

C57BL/6 (B6) male donor mice were used for BMT and purchased from Janvier (St Berthevin Cedex, France). BALB/c male recipient mice were obtained from Charles River Laboratories (Sulzfeld, Germany). At the time point of BMT, mice were 9 weeks old. Animals were housed in individual ventilated cages and received analgesic treatment with metamizole. The local authority of Lower Saxony/Germany approved the animal experiments (no. 14/1448). The ethical guidelines for animal care and experimental use were fulfilled.

Acute GvHD was induced by total body irradiation of BALB/c mice at $9.5 \mathrm{~Gy}$ with subsequent BMT after $24 \mathrm{hrs}$. For BMT, $10^{7}$ bone marrow cells and $2 \times 10^{6}$ purified T cells from B6 donor spleen and lymph node were injected into the tail vein of each recipient mice (modified according to Tischner, et al.) [29]. The GvHD pathology score was based on activity, posture, diarrhea and the condition of the fur and skin. For each of the four criteria $0-2$ points were assigend according to severity with a maximum of 8 points for all criteria together. Animals reaching 6 points were sacrificed immediately for ethical reasons by $\mathrm{CO} 2$ inhalation followed by cervical dislocation. Mice which did not reach 6 points during the observation period were sacrificed 42 days after BMT. The GvHD severity score and the weight of the animals were assessed daily.

For ECP in vivo therapy, $1.5 \times 10^{6} \mathrm{UVA} / 8$-MOP or UVC irradiated splenocytes from $\mathrm{C} 3 \mathrm{H}$ donor mice were resuspended in $100 \mu \mathrm{PBS}$ and injected in the lateral mouse tail vein of the $B A L B / c$ recipient mice. The control group received PBS only. The first injection was performed three days after BMT followed by four ECP treatments at weekly intervals.

\section{Flow cytometry analysis}

For the in vitro analysis of human mononuclear cells, we used the following anti-human antibodies: CD3 Pacific Blue (OKT3), CD4 PE (RPA-T4), CD8 PE (SK1), CD14 Pacific Blue (M5E2), CD19 PE (HIB19), CD56 PE (HCD56), and CD39 PE (A1), which were purchased from BioLegend (San Diego, USA; clone name in brackets). Detection of early and late apoptosis was performed by Annexin V (FITC) and 7-AAD viability staining (BioLegend).

For the in vivo GvHD experiments, the following anti-mouse antibodies were used: CD3 Pacific Blue (eBio500A2), CD4 FITC (RM 4-5), CD25 PE (PC 61.5), and FoxP3 APC (FJK-16s), purchased from eBioscience (San Diego, USA); CD8 APC (53-6.7) and CD49b APC (DX5) from BioLegend. Flow cytometry analysis was perfomed with a FACS Canto II instrument (BD Biosciences, San Jose, USA).

\section{Statistics}

For statistical analysis of the in vitro apoptosis experiments, a twoway repeated measures analysis of variance (ANOVA) was performed. ANOVA was followed by subgroup analysis with Tukey's post hoc test. Statistical significance was assumed for p-values $<0.05$. Bar diagrams are shown as mean \pm standard deviation (SD). Levels of statistical significance are indicated above the bars. Comparison of the leukocyte frequencies in vivo were performed with the non-parametric MannWhitney U-test. Survival was analysed by log-rank-test. Graph Pad Prism 7.00 served as statistical analysis software (San Diego, USA).

\section{Results}

\section{Apoptosis induction in human mononuclear cells by UV-A/8-MOP} compared to UV-C treatment

We started the experiments with a UV dose of $2 \mathrm{~J} / \mathrm{cm}^{2}$ for both UV-A and UV-C irradiation. 8-MOP and UV-A treatment resulted in a strong increase of apoptosis reaching $86-94 \%$ in $\mathrm{CD} 4^{+}$and $\mathrm{CD} 8^{+} \mathrm{T}$ cells, $84 \%$ in $\mathrm{CD}_{14} 4^{+}$monocytes, $94 \%$ in $\mathrm{CD} 19^{+} \mathrm{B}$ cells, $92 \%$ in $\mathrm{CD}^{+}$ $\mathrm{CD}^{+}{ }^{+}$Treg cells and $96-97 \%$ in CD3 $\mathrm{CD}^{-} 6^{+} \mathrm{NK}$ and $\mathrm{CD}^{+} \mathrm{CD}^{+} 6^{+}$ NKT cells after 72 hrs in vitro (Figure 1, black columns). Irradiation with $2 \mathrm{~J} / \mathrm{cm}^{2} \mathrm{UVC}$ also induced a strong increase in apoptosis within $72 \mathrm{hrs}$, but the level of apoptosis was clearly lower compared to the 8-MOP/UVA treatment in almost all cell types (Figure 1). After $72 \mathrm{hrs,}$ we observed apoptosis levels of 51-62 \% in CD4 $4^{+}$and $\mathrm{CD}^{+} \mathrm{T}$ cells, 74 $\%$ in $\mathrm{CD} 14^{+}$monocytes, $67 \%$ in $\mathrm{CD} 19^{+} \mathrm{B}$ cells, $72 \%$ in $\mathrm{CD} 4^{+} \mathrm{CD} 39^{+}$ Treg cells and $74-80 \%$ in CD $3-\mathrm{CD}^{-} 6^{+} \mathrm{NK}$ and $\mathrm{CD}^{+} \mathrm{CD}^{+} 6^{+} \mathrm{NKT}$ cells (Figure 1; white columns). In the UV-C group, the CD14 ${ }^{+}$monocytes reached a relatively high apoptosis level, whereas within in the 8-MOP/ UV-A group they reached a slightly lower apoptosis level compared to the other cell types (Figure 1). 
A.

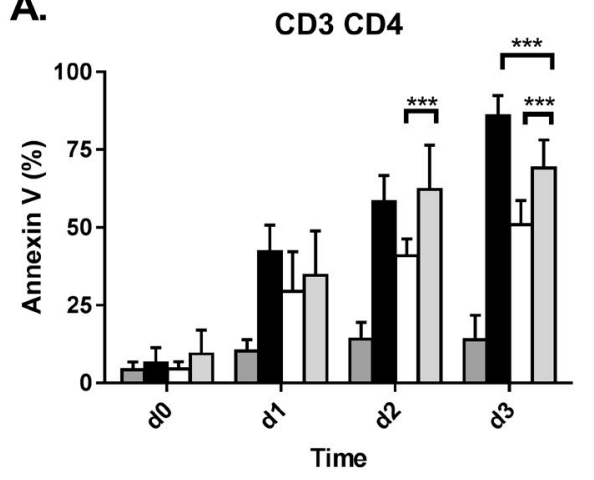

c.

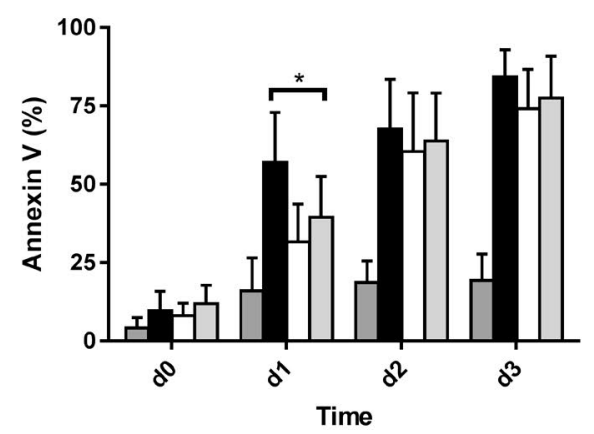

E.

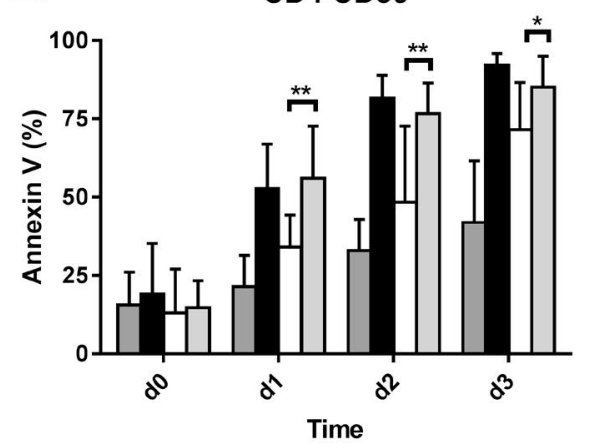

G.

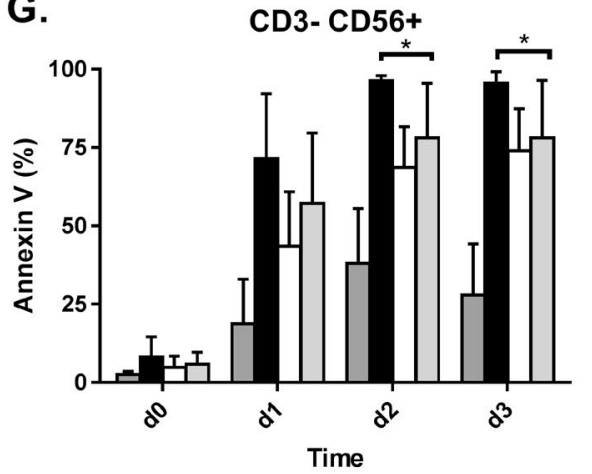

B.

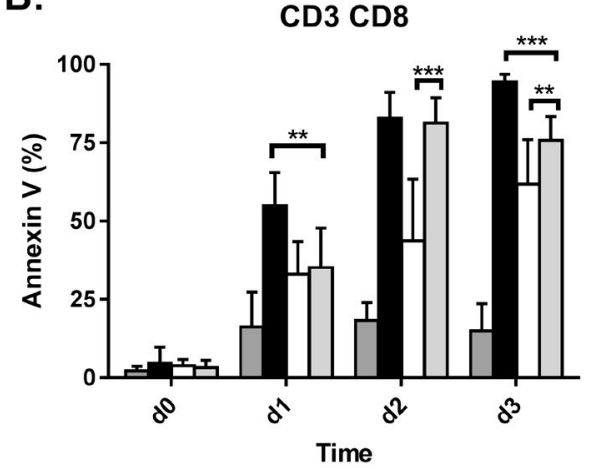

D.

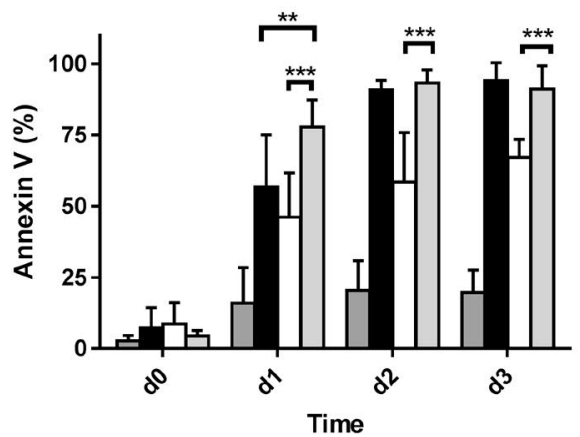

F.

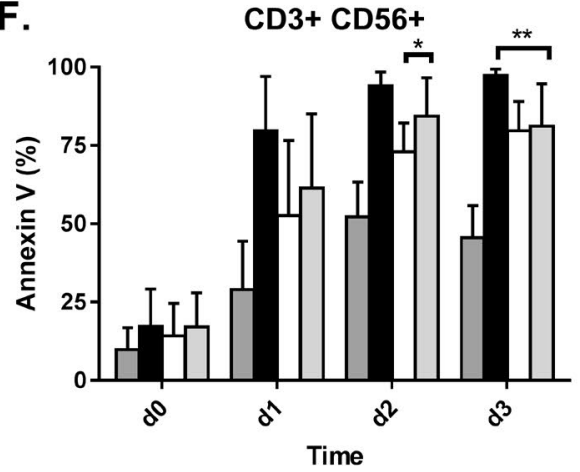

Figure 1. Apoptosis kinetics after treatment with 8-MOP+UV-A compared to UV-C without 8-MOP. Mononuclear cells were purified from human buffy coats. Untreated cells as well as 8-MOP+UV-A $\left(2 \mathrm{~J} / \mathrm{cm}^{2}\right)$ and UV-C $\left(2\right.$ and $\left.6 \mathrm{~J} / \mathrm{cm}^{2}\right)$ treated cells were cultured ex vivo for $72 \mathrm{hrs}$ and stained on a daily basis using AnnexinV as an early apoptosis marker ( $\left.\mathrm{n}=9-12\right)$. Bars represent the mean $+\mathrm{SD}$. Statistical significance was determined by two-way ANOVA followed by Tukey's multiple comparison test $(* \mathrm{p}<0.05 ; * * \mathrm{p}<0.01 ; * * * \mathrm{p}<0.001)$ 
A critical feature especially concerning UV-C irradiation is the absorption of UV-C light by the material of the cell culture flask or irradiation bag. We measured the reduction of the effective UV dose after passing the plastic material of the cell culture flask. We found a loss of UV-C dosage of $70 \%$, which means an effective UV-C dose on the cell surface of only $0.6 \mathrm{~J} / \mathrm{cm}^{2}$. In contrast, the loss of UVA intensity after passing the plastic surface was only $10 \%$, resulting in an effective cell dose of $1.8 \mathrm{~J} / \mathrm{cm}^{2}$. Hence, we increased the UV-C irradiation setting to $6 \mathrm{~J} / \mathrm{cm}^{2}$, which corresponds to an effective cellular dose of $1.8 \mathrm{~J} / \mathrm{cm}^{2}$.

Notably, the increase in UV-C dosage to $6 \mathrm{~J} / \mathrm{cm}^{2}$, significantly increased cellular apoptosis. Accordingly, after $72 \mathrm{hrs,} \mathrm{we} \mathrm{measured}$ apoptosis levels of $69-76 \%$ in the $\mathrm{CD}^{+}$and $\mathrm{CD}^{+} \mathrm{T}$ cells, $76 \%$ in $\mathrm{CD} 14^{+}$ monocytes, $91 \%$ in $\mathrm{CD} 19^{+} \mathrm{B}$ cells, $85 \%$ in $\mathrm{CD} 4^{+} \mathrm{CD} 39^{+}$Treg cells and $78-81 \%$ in $\mathrm{CD}^{-} \mathrm{CD}^{+} 6^{+} \mathrm{NK}$ and $\mathrm{CD}^{+} \mathrm{CD}^{+} 6^{+} \mathrm{NKT}$ cells (Figure 1; grey columns). In monocytes, B cells and Treg cells, irradiation with an effective dose of $1.8 \mathrm{~J} / \mathrm{cm}^{2} \mathrm{UVC}\left(6 \mathrm{~J} / \mathrm{cm}^{2}\right.$ setting for the UV-C lamps) reached similar apoptosis levels compared to the effective dose of 1.8 $\mathrm{J} / \mathrm{cm}^{2} \mathrm{UVA}+8$-MOP (Figure $1 \mathrm{~A}, 1 \mathrm{~B}$ and $1 \mathrm{E}$ ). The final apoptosis rate reached in $\mathrm{CD}^{+}$and $\mathrm{CD} 8^{+} \mathrm{T}$ cells in the UV-C group was $7.6-9.0$ $\%$ less than in the UVA +8 -MOP group. NK and NKT cells showed apoptosis levels that were $12.9-17.2 \%$ less than in the UVA + 8-MOP group (Figure $1 \mathrm{~F}$ and $1 \mathrm{G}$ ).

Late apoptosis is characterized by AnnexinV and 7-AAD costaining. After $72 \mathrm{hrs}$ in cell culture, the comparison of $2 \mathrm{~J} / \mathrm{cm}^{2} \mathrm{UV}-\mathrm{A}$ $\left(1.8 \mathrm{~J} / \mathrm{cm}^{2}\right.$ effective dose) and UV-C $6 \mathrm{~J} / \mathrm{cm}^{2}\left(1.8 \mathrm{~J} / \mathrm{cm}^{2}\right.$ effective dose $)$ revealed similar levels of late apoptotic cells in the $\mathrm{CD} 4^{+} \mathrm{T}$ cells, $\mathrm{CD} 14^{+}$ monocytes, $\mathrm{CD} 19^{+} \mathrm{B}$ cells and $\mathrm{CD} 3 \mathrm{CD}^{-} 6^{+} \mathrm{NK}$ cells (Figure $\mathrm{S} 1$ ). $\mathrm{CD} 14^{+}$ monocytes were characterized by very low levels of less than $30 \%$ of late apoptotic cells in both groups (Figure S1 C). CD8 ${ }^{+} \mathrm{T}$ cells showed slightly increased levels of late apoptosis in the UV-C group, whereas
$\mathrm{CD}^{+}{ }^{+} \mathrm{CD} 39^{+}$Treg cells and $\mathrm{CD} 3{ }^{+} \mathrm{CD} 56^{+}$NKT cells showed increased late apoptosis in the UV-A group (Figure S1 C).

\section{Therapy of GvHD in mice with UV-A/8-MOP or UV-C treated splenocytes}

For our in vivo study, we used a mouse model of acute GvHD. The disease was induced in conditioned $\mathrm{BALB} / \mathrm{c}$ mice by transplantation with B6 bone marrow and T cells. Mice were injected with splenocytes either treated with 8-MOP/UV-A or UV-C therapy, or PBS as a control. Although the Log-rank test did not reach significance $(\mathrm{p}=0.136)$, the median survival time in the UV-C group was 28.5 days compared to only 23 days in the conventional 8-MOP/UVA group (Figure 2A, $n=17-18$ ). It is noteworthy that the median survival of the PBS control group was 27 days.

We did not observe any significant differences in the daily assessed GvHD score between the three experimental groups (Figure 2B). Also the weight loss was not significantly different between the three groups (Figure 2C; ANOVA p=0.09).

\section{Cellular analysis of mouse splenocytes after therapeutic treatment with UV-A/8-MOP or UV-C in vivo}

Splenocytes of GvHD mice of all three experimental groups were prepared and enumerated after sacrificing the animals when reaching the end of the observation time after 42 days or a GvHD score of 6 . We observed a slightly increased level of the CD3 $\mathrm{CD}^{-} 9 \mathrm{~b}^{+} \mathrm{NK}$ cells in the UV-C treated group compared to the UV-A/8-MOP group (Figure $3 \mathrm{~A})$. Furthermore, the percentage of the $\mathrm{CD}^{+} \mathrm{CD}^{+} 9 \mathrm{~b}^{+} \mathrm{NKT}$ cells was increased in the UV-C group, too (Figure $3 \mathrm{~B}$ ). Quantification of the percentages of $\mathrm{CD}^{+} \mathrm{CD}^{+} \mathrm{T}$ cells, the $\mathrm{CD}^{+} \mathrm{CD}^{+} \mathrm{T}$ cells and $\mathrm{CD} 4^{+}$ $\mathrm{CD}_{25}{ }^{+} \mathrm{FoxP}^{+}$Treg cells revealed no differences between UV-C, UV$\mathrm{A} / 8-\mathrm{MOP}$ and $\mathrm{PBS}$ control group (Figure 3C-3E).
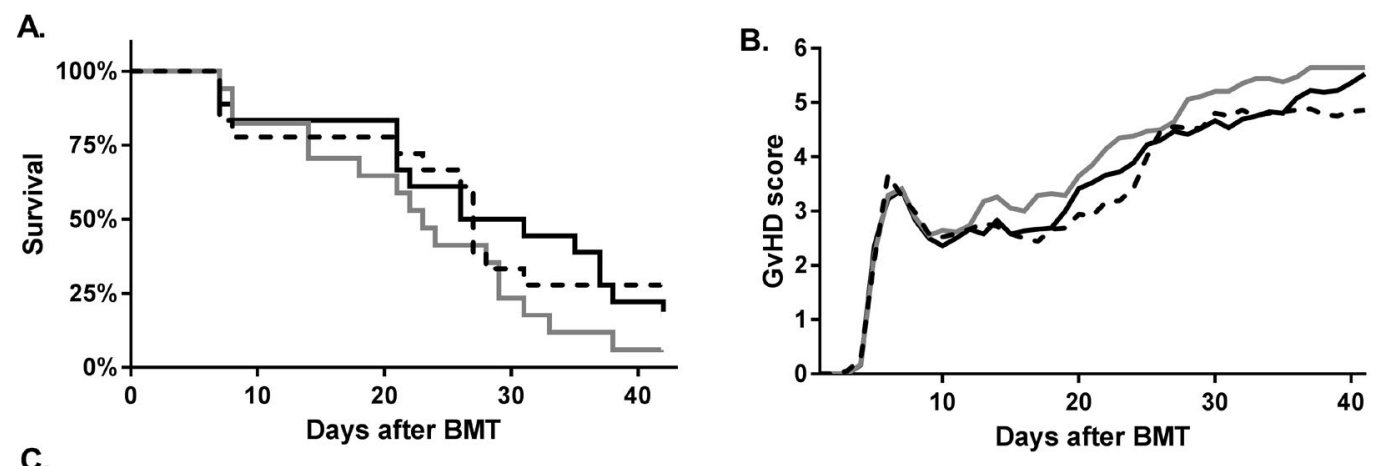

C.
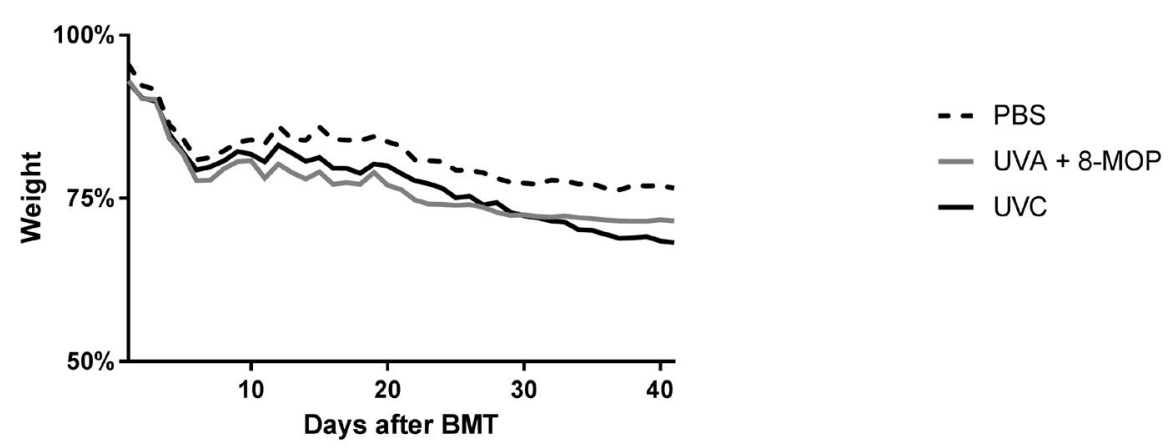

Figure 2. Therapeutic efficacy of 8-MOP/UV-A and UV-C treatment in a mouse model of acute GvHD. Acute GvHD was induced by transplantation of B6 bone marrow and T cells into conditioned BALB/c recipient mice. Animals received five injections in weekly intervals of $1.5 \times 10^{6} \mathrm{C} 3 \mathrm{H}$ splenocytes treated with 8 -MOP/UV-A, UV-C or PBS only as a control ( $\mathrm{n}=17-18$ ). Survival (a), the GvHD severity score (b) and weight loss (c) are depicted in the graphs 

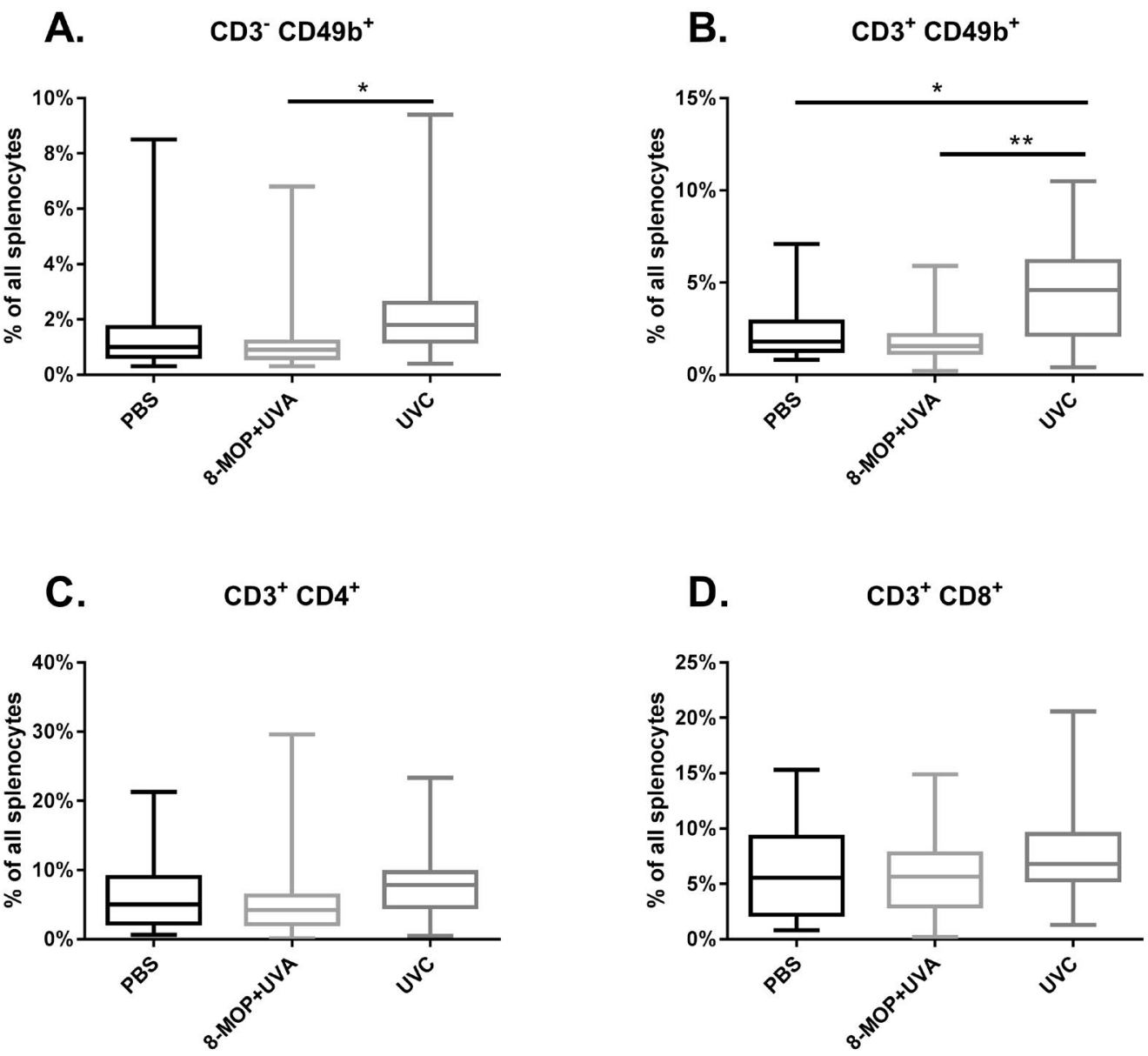

D. $\quad \mathrm{CD}^{+} \mathrm{CD}^{+}$

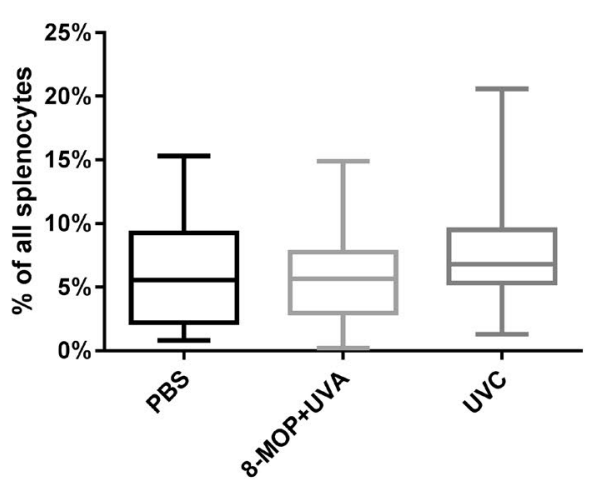

\section{E. $\quad \mathrm{CD}^{+} \mathrm{CD}^{+} 5^{+} \mathrm{FoxP}^{+}$}

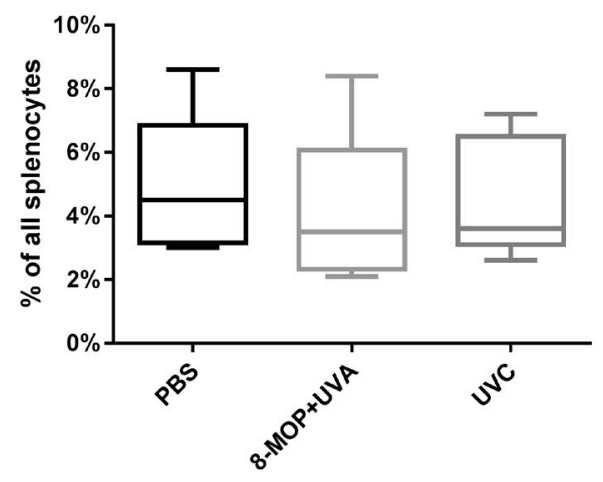

Figure 3. Flow cytometric enumeration of leukocyte subsets after treatment GvHD mice with 8-MOP/UV-A and UV-C. GvHD mice received five injections in weekly intervals of $1.5 \mathrm{x}$ $10^{6} \mathrm{C} 3 \mathrm{H}$ splenocytes treated with 8-MOP/UV-A $(n=8-15)$, UV-C $(n=5-18)$ or PBS as a control $(n=9-16)$. Splenocytes were prepared at the end of the observation period of 42 days or when reaching a GvHD Score of 6 . Box plots are shown with median, quartiles and $\min / \max$ values $(* \mathrm{p}<0.05)$

\section{Discussion}

Cellular apoptosis is a control mechanism for immune cell homeostasis. To prevent inflammatory reactions, a steady state level of apoptotic cells seems to be favorable whereas a low or high number of apoptotic cells is probably not beneficial [31,32]. Since conventional ECP with 8-MOP/UV-A treatment shows high therapeutic potential in many GvHD patients, the apoptosis pattern of this therapeutic regimen was chosen as the basis for the apoptosis adjustment of the new UV-C treatment.

Application of 8-MOP and $2 \mathrm{~J} / \mathrm{cm}^{2} \mathrm{UV}$-A irradiation resulted in a gradual rise of apoptosis reaching levels of about $90 \%$ after $72 \mathrm{hrs}$ of treatment. These findings correspond to the results of other groups and confirm our earlier observations $[14,20,33]$. The clinical standard UV-A irradiation dose is $2 \mathrm{~J} / \mathrm{cm}^{2}$. In our UV-C test series we thus started with 
the same dose of $2 \mathrm{~J} / \mathrm{cm}^{2}$, which resulted in significantly lower final apoptosis rate $72 \mathrm{hrs}$ after treatment. This finding is most likely the result of the high absorption of UV-C irradiation by the plastic material of the culture flask in which we treated the cells. Our subsequent measurements revealed absorption of $70 \%$ of the UV-C radiation by the plastic surface, whereas only $10 \%$ of the UV-A radiation was lost by passing the plastic material. This is a crucial point to keep in mind. Every ECP radiation bag should be measured for its UV absorption rate when using UV-C as an experimental source of irradiation. The UV-C dose increase to $6 \mathrm{~J} / \mathrm{cm}^{2}$ led to the same effective cellular dose of $1.8 \mathrm{~J} / \mathrm{cm}^{2}$ compared to the UV-A irradiation. This resulted in a significant increase of apoptosis in most leukocyte subpopulations. The apoptosis levels of this UV-C treated series were comparable or at least approached the levels of the conventional 8-MOP/UV-A treatment. The apoptosis levels in T cells in the UV-C groups did not reach the level of the 8-MOP/UV-A group. However, further increase of the UV-C dose would probably solve this problem. In addition to our results, Pohler and colleagues could show that UVC use for T-cell inactivation in platelet products was linked to reduced T cell proliferation, cytokine secretion and antigen presentation [30]. Another important cell type in ECP research and our apoptosis experiments are monocytes. In contrast to the other cell types investigated in our study, the monocytes were vulnerable to apoptosis induction already in the $2 \mathrm{~J} / \mathrm{cm}^{2}(0.6 \mathrm{~J} /$ $\mathrm{cm}^{2}$ effective dose) low dose UV-C setting. In monocytes we found no difference in the apoptosis kinetic or the final apoptosis rate 72 hrs after treatment with $2 \mathrm{~J} / \mathrm{cm}^{2}$ compared to $6 \mathrm{~J} / \mathrm{cm}^{2}$. Another aspect concerning the monocyte population is the very low number of Annexin V and 7-AAD double-positive late-apoptotic cells. This is a very interesting finding considering the conflicting results of different studies on monocyte apoptosis in ECP therapy. Several groups found 8-MOP/UV-A induced monocytes apoptosis to be comparable to other cell types $[20,24,34,35]$. In contrast, other groups reported a relatively high resistance of monocyte towards 8-MOP/UV-A induced apoptosis $[36,37]$. With our results of normal or slightly reduced levels of early monocyte apoptosis, but strongly reduced late monocyte apoptosis we can now join both sides of the scientific discussion about the induction of monocyte apoptosis by ECP.

Our in vivo results concerning the treatment of acute murine GvHD with 8-MOP/UV-A compared to UV-C are difficult to interpret. The limitation of the in vivo part is the lack of therapeutic significance of the conventional 8-MOP/UV-A treatment group compared to the PBS treated control group. However, the UV-C treatment group showed at least a tendency to a higher survival rate compared to the conventional 8-MOP/UV-A therapy, especially in the last weeks of the observation period. Even though the benefit of UV-C therapy did not reach statistical significance, we found that the therapeutic response was at least not worse than the one of the 8-MOP/UV-A treatment. Given the fact that the conventional 8-MOP/UV-A based ECP showed therapeutic effects in thousands of patients worldwide, and combining this information with our in vivo result that UV-C seems not to be worse compared to $8-\mathrm{MOP} / \mathrm{UV}$-A treatment, the UV-C approach could be indeed an interesting alternative. However, the final therapeutic potential of the $\mathrm{UV}-\mathrm{C}$ approach has to be investigated in future animal and clinical studies.

The cellular assessment of leukocyte subpopulations from the three experimental groups did not show any significant differences. The slightly increased percentages of NK and NKT cells in the UV-C group may not be linked to therapeutic effects. Nevertheless, this finding fits very well with the results of Iniesta and colleagues who showed that an increase of NK cells could be a predictive biomarker for the response to ECP in GvHD therapy [38].

In addition to the restoration of immune homeostasis by apoptotic cells, Edelson and colleagues demonstrated an ECP mechanism based on the activation of platelets during the ex vivo processing and the subsequent interaction of these platelets with monocytes leading to the induction of tolerogenic dendritic cells [39]. We expect that this mechanism should not differ between the conventional 8-MOP/UV-A and the novel UV-C approach, because the apheresis procedure would be the same.

In conclusion, we found similar apoptosis kinetics as well as final apoptosis levels after in vitro treatment of mononuclear cells with UV-C compared to the conventional 8-MOP/UV-A procedure. The GvHD mouse model did not show any statistically significant evidence for the new therapeutic concept when comparing the new UV-C with the conventional 8-MOP/UV-A treatment, but we also did not observe any adverse side effects regarding survival or GvHD score. Thus, in our opinion, the concept of an ECP protocol without 8-MOP using UV-C irradiation deserves further investigation.

\section{Conflict of interest}

The authors declare no conflict of interest.

\section{References}

1. Golombek DA, Rosenstein RE (2010) Physiology of circadian entrainment. Physiol Rev 90: 1063-1102. [Crossref]

2. Brown AJ, Pendergast JS, Yamazaki S (2019) Peripheral Circadian Oscillators. Yale J Biol Med 92: 327-335. [Crossref]

3. Pritchard C, Silk A, Hansen L (2019) Are rises in Electro-Magnetic Field in the human environment, interacting with multiple environmental pollutions, the tripping point for increases in neurological deaths in the Western World? Med Hypotheses 127: 76-83. [Crossref]

4. Pall ML (2018) Wi-Fi is an important threat to human health. Environ Res 164: 405416. [Crossref]

5. Panagopoulos DJ, Johansson O, Carlo GL (2015) Polarization: A Key Difference between Man-made and Natural Electromagnetic Fields, in regard to Biological Activity. Sci Rep 5: 14914.

6. Di Ciaula A (2018) Towards 5G communication systems: Are there health implications? Int J Hyg Environ Health 221: 367-375. [Crossref]

7. Russell CL (2018) 5G wireless telecommunications expansion: Public health and environmental implications. Environ Res 165: 484-495. [Crossref]

8. Kostoff RN, Heroux P, Aschner M, Tsatsakis A (2020) Adverse health effects of 5G mobile networking technology under real-life conditions. Toxicol Lett 323: 35-40. [Crossref]

9. Hardell L (2017) World Health Organization, radiofrequency radiation and health - a hard nut to crack. Int J Oncol 51: 405-413. [Crossref]

10. Deruelle F (2020) The different sources of electromagnetic fields: Dangers are not limited to physical health. Electromagn Biol Med 39: 166-175. [Crossref]

11. Zeiser R (2019) Advances in understanding the pathogenesis of graft-versus-host disease. Br J Haematol 187: 563-572. [Crossref]

12. Cho A, Jantschitsch C, Knobler R (2018) Extracorporeal Photopheresis-An Overview Front Med 5: 236. [Crossref]

13. Vieyra-Garcia PA, Wolf P (2020) Extracorporeal Photopheresis: A case of immunotherapy ahead of its time. Transfus Med Hemother 47: 226-235. [Crossref]

14. Bladon J, Taylor PC (2006) Extracorporeal photopheresis: a focus on apoptosis and cytokines. J Dermatol Sci 43: 85-94. [Crossref]

15. Marques MB, Adamski J (2014) Extracorporeal photopheresis: technique, established and novel indications. J Clin Apher 29: 228-234. [Crossref] 
16. Kuzmina Z, Stroncek D, Pavletic SZ (2015) Extracorporeal photopheresis as a therapy for autoimmune diseases. J Clin Apher 30: 224-237. [Crossref]

17. Franklin C, Cesko E, Hillen U, Schilling B, Brandau S (2015) Modulation and Apoptosis of Neutrophil Granulocytes by Extracorporeal Photopheresis in the Treatment of Chronic Graft-Versus-Host Disease. PLoS One 10: e0134518. [Crossref]

18. Pilon C, Stehlé T, Beldi-Ferchiou A, Matignon M, Thiolat A, et al. (2019) Human Apoptotic Cells, Generated by Extracorporeal Photopheresis, Modulate Allogeneic Immune Response. Front Immunol 10: 2908. [Crossref]

19. Mankarious M, Matthews NC, Snowden JA, Alfred A (2020) Extracorporeal Photopheresis (ECP) and the Potential of Novel Biomarkers in Optimizing Management of Acute and Chronic Graft vs. Host Disease (GvHD). Front Immunol 11: 81. [Crossref]

20. Budde H, Berntsch U, Riggert J, Legler TJ (2017) In vitro effects of different 8-methoxypsoralen treatment protocols for extracorporeal photopheresis on mononuclear cells. Cent Eur J Immunol 42: 1-9. [Crossref]

21. Johnson R, Staiano-Coico L, Austin L, Cardinale I, Nabeya-Tsukifuji R, et al. (1996) PUVA treatment selectively induces a cell cycle block and subsequent apoptosis in human T-Lymphocytes. Photochem Photobiol 63: 566-571. [Crossref]

22. Elliott MR, Koster KM, Murphy PS (2017) Efferocytosis Signaling in the Regulation of Macrophage Inflammatory Responses. J Immunol 198: 1387-1394. [Crossref]

23. Nagata S (2018) Apoptosis and Clearance of Apoptotic Cells. Annu Rev Immunol 36: 489-517. [Crossref]

24. Lamioni A, Parisi F, Isacchi G, Giorda E, Di Cesare S, et al. (2005) The immunological effects of extracorporeal photopheresis unraveled: induction of tolerogenic dendritic cells in vitro and regulatory $\mathrm{T}$ cells in vivo. Transplantation 79: 846-50. [Crossref]

25. Wei BM, Hanlon D, Khalil D, Han P, Tatsuno K, et al. (2020) Extracorporeal Photochemotherapy: Mechanistic Insights Driving Recent Advances and Future Directions. Yale J Biol Med 93: 145-159. [Crossref]

26. Darvekar S, Juzenas P, Oksvold M, Kleinauskas A, Holien T, et al. (2020) Selective Killing of Activated T Cells by 5-Aminolevulinic Acid Mediated Photodynamic Effect: Potential Improvement of Extracorporeal Photopheresis. Cancers 12: 377. [Crossref]

27. Cloud TM, Hakim R, Griffin AC (1961) Photosensitization of the eye with methoxysalen. II. Chronic effects. Arch Ophthalmol 66: 689-694. [Crossref]

28. van Iperen HP, Beijersbergen van Henegouwen GM (1996) Photopheresis; the risk of photoallergy. J Photochem Photobiol B 34: 225-228. [Crossref]
29. Godar DE (1999) Light and death: photons and apoptosis. J Investig Dermatol Symp Proc 4: 17-23. [Crossref]

30. Pohler P, Müller M, Winkler C, Schaudien D, Sewald K, et al. (2015) Pathogen reduction by ultraviolet $\mathrm{C}$ light effectively inactivates human white blood cells in platelet products. Transfusion 55: 337-347. [Crossref]

31. Tischner D, Theiss J, Karabinskaya A, van den Brandt J, Reichardt SD, et al. (2011) Acid sphingomyelinase is required for protection of effector memory $\mathrm{T}$ cells against glucocorticoid-induced cell death. J Immunol 187: 4509-4516 [Crossref]

32. Grodzicky T, Elkon KB (2002) Apoptosis: a case where too much or too little can lead to autoimmunity. Mt Sinai J Med 69: 208-19. [Crossref]

33. Enomoto DN, Schellekens PT, Yong SL, ten Berge IJ, Mekkes JR, et al. (1997) Extracorporeal photochemotherapy (photopheresis) induces apoptosis in lymphocytes: a possible mechanism of action of PUVA therapy. Photochem Photobiol 65: 177-80. [Crossref]

34. Legitimo A, Consolini R, Failli A, Fabiano S, Bencivelli W, et al. (2007) In Vitro Treatment of Monocytes With 8-methoxypsolaren and Ultraviolet A Light Induces Dendritic Cells With a Tolerogenic Phenotype. Clin Exp Immunol 148: 564-72. [Crossref]

35. Setterblad N, Garban F, Weigl R, Assier E, Drillat P, et al. (2008) Extracorporea Photophoresis Increases Sensitivity of Monocytes From Patients With Graft-VersusHost Disease to HLA-DR-mediated Cell Death. Transfusion 48: 169-177. [Crossref]

36. Yoo EK, Rook AH, Elenitsas R, Gasparro FP, Vowels BR (1996) Apoptosis Induction of Ultraviolet Light A and Photochemotherapy in Cutaneous T-cell Lymphoma: Relevance to Mechanism of Therapeutic Action. J Invest Dermatol 107: 235-242. [Crossref]

37. Yakut E, Jakobs C, Peric A, Michel G, Baal N, et al. (2015) Extracorporeal Photopheresis Promotes IL-1 $\beta$ Production. J Immunol 194: 2569-2577. [Crossref]

38. Iniesta P, Revilla N, Chen-Liang TH, Hurtado AM, Vicente V, et al. (2018) An early increase of CD56bright natural killer subset as dominant effect and predictor of response to extracorporeal photopheresis for graft-versus-host disease. Transfusion 58: 2924-2932. [Crossref]

39. Durazzo TS, Tigelaar RE, Filler R, Hayday A, Girardi M, et al. (2014) Induction of monocyte-to-dendritic cell maturation by extracorporeal photochemotherapy: initiation via direct platelet signaling. Transfus Apher Sci 50: 370-378. [Crossref]

Copyright: (C2021 Budde H. This is an open-access article distributed under the terms of the Creative Commons Attribution License, which permits unrestricted use, distribution, and reproduction in any medium, provided the original author and source are credited. 